\title{
DE COMO SE PERDER NA TRADUÇÃO
}

\author{
Pedro de Souza \\ Universidade Federal de Santa Catarina \\ pedesou@gmail.com
}

\begin{abstract}
Resumo: O objeto deste artigo é a tradução como experiência e ato de escrita. O ponto de partida aqui é processo tradutório como desafio de escrever entre duas línguas, isto é, nem na língua de partida, nem na língua de chegada. Refletimos o entremeio do ato de traduzir em que a transposição de um texto de uma língua para outra implica em perda, tanto de sentido, quanto de palavras. A perspectiva adotada para essa reflexão é a da relação entre sujeito, língua e discurso, conforme propõe a escola francesa de análise de discurso
\end{abstract}

Palavras-chave: Escrita, discurso, sentido, tradução, subjetividade.

\begin{abstract}
The object of this article is the translation as experience and act of writing. The starting point is the text version process as challenge to write between two languages, that is, nor in the language of departure, nor in the language of arrival. I intend to reflect about the act to translate where the transposition of a text from a language to another implies in loss, as much in semantic terms, as in terms of words. The perspective adopted for this reflection is the relation between translator, language and speech, as it considers the French school of speech analysis.
\end{abstract}

Keywords: Writing, speech, meaning, translation, subjectivity.

Gostaria de propor elementos para pensar a tradução como experiência de escritura, focalizando-a no espaço em que o tradutor, ora por déficit de palavras, ora por déficit de sentido, se perde na transposição de um texto para outra língua. Proponho uma abordagem que visa captar o processo deslizante do trabalho da tradução. $\mathrm{O}$ que me interessa, assentado em perspectiva discursiva da relação 
entre sujeito, língua e discurso, é observar a dimensão singular do acontecimento que torna possível uma experiência de escrita no espaço entre duas línguas. Precisamente, neste breve artigo, exponho elementos para uma abordagem em que o erro em tradução pode trazer vestigios do que permanece incontornável na experiência de traduzir, a saber, o inevitável estranhamento de sempre dizer com palavras de outro.

Parto da noção de deslize, desenvolvida por Eni Orlandi ${ }^{1}$ a partir de Michel Pêcheux ${ }^{2}$. O deslize é o termo adotado por Orlandi para descrever o movimento instável da interpretação que antecede a qualquer possibilidade de sentido. Interpretar, pois, é produzir, no tecido da linguagem, um esgarçamento, um rasgão. Figurativamente, aludo ao deslizamento que desloca, transfere o já dito localizado em dada série histórica do dizer para outra em vias de se realizar em um momento dado de enunciação.

Isso é o que explica, nos termos de Pêcheux ${ }^{3}$, a exposição ao equivoco inerente à língua e portanto a tudo que se realiza nela e com ela. Sob esse aspecto, a ideia de transferência aparece como traço próprio da metáfora ou do efeito metafórico, ou seja, a propriedade intrínseca que permite a todo enunciado tornar-se outro, diferir de si mesmo, deixar-se transportar do ambiente discursivo em que se provê de sentido para alocar-se em outro regime de discurso.

Esse deslizamento de enunciados, transmutando-se entre o mesmo e o diferente, em que um é parte constitutiva de outro descreve a especificidade da língua e do discurso, termos que formam entre si um emaranhado de relações enredando formulações linguísticas e modos pré-construídos de interpretações. A língua é sintaxe exposta ao jogo, diz Pêcheux ${ }^{4}$, - o que quebra a rigidez de sua sistematicidade - e o discurso é o ato de dizer que inscreve os efeitos linguísticos nas relações de sentido que compõem a história ${ }^{5}$.

Nesses termos, ler ou escrever demanda a entrada em um terreno escorregadio em que o dizer do qual se parte e ao qual se chega são sequências linguísticas arroladas em séries de pontos de deriva demandando interpretação. Para o sujeito que se produz nesta exposição ao equívoco da língua e à interpelação da ideologia, a questão 
gira sempre em torno do como dizer diferentemente o mesmo. Nisto consiste a obrigação de interpretar. Em Análise de Discurso, tudo isso é observado no exercício monolíngue do dizer. Como seria pensar o sujeito, efeito de equívoco, enunciando não mais fixado apenas em certo sistema linguístico, mas no seu dizer em trânsito entre uma língua e outra? O que se passa quando o caso não é falar uma mesma língua de muitos modos, mas simplesmente falar em mais de uma, sendo incitado a transferir relações de sentido e interpelado no ponto em que simbolicamente um espaço linguístico é irredutível a outro, e que portanto são mutuamente irredutíveis os sentidos que se processam em distintos territórios linguísticos?

Essas perguntas já introduzem um modo discursivo de abordar o ato de traduzir. De minha parte, como em outros trabalhos, pretendo flagrar o movimento da subjetividade, não no lugar da cadeia discursiva em que o sujeito já está ideologicamente interpelado e impedido de dizer de outra maneira, mas no trecho do circuito enunciativo em que algo resiste revelando sintomaticamente pontos em que a ideologia falha determinando hesitação. Pode-se entrever, na prática da tradução, como se desloca o percurso de constituição subjetiva aí envolvido. De um lado, o sujeito que traduz pode aparecer, graças a um discurso que o interpela e legitima seu ato tradutório; por outro, arrisca-se a perder-se nas vacilações suscitadas pela busca da formulação que melhor corresponda à de partida.

Mais que reformulação, o texto em estado de passagem para outra língua é superfície tópica a ser cartografada em discurso. Reformular pressupõe repetir em outra fórmula. $\mathrm{Na}$ tradução, o sujeito que traduz deve dobrar-se ao ato de enunciar no ponto em que faz um mesmo sentido transitar para outra língua. É inerente ao dizer que ele - sob modalidade oral ou escrita - aconteça exposto a repetição em uma mesma ou outra língua. Redizer, renunciar noutra língua, ou repetir em um modo estrangeiro de dizer, eis uma definição possível da experiência de traduzir.

Mas o movimento da tradução deve instaurar um outro tempo para o dizer Abre-se, no ato de traduzir, uma temporalidade enunciativa em que a tentativa de repetir a palavra em outra forma signi- 
ficante expõe a palavra como pura diferença de sentidos. Trata-se, em verdade, de um jogo de regras, no qual um evento enunciativo escritural deixa-se re-escriturar em outra língua escancarando diferenças e repetições mutuamente referendadas nos sistemas linguísticos postos em conexão pelo processo tradutório.

Tomada no âmbito da história e do discurso, a passagem de um ato de enunciação para outra língua não acontece sem interpelação. Isso implica dizer que o sujeito que traduz não pode se constituir a não ser perdendo-se na turbulência dos discursos que se encarregam do destino do dizer submetido à passagem. Pelo viés da Análise de Discurso, diz-se que a passagem do dizer de uma para outra série de enunciados implica esquecimento. Não me refiro apenas ao campo de luta entre sentidos, contexto agonístico no qual para que um sentido sobreviva é preciso que outro seja abatido até desaparecer da memória. É que antes de se decidir por um sentido ou outro, a matéria significante passa por um estágio de turbulência, de exposição ao excesso em que tudo e nada pode ser tomado como seu significado. Ante à força ideológica que rege a injunção de traduzir, trata-se então de esquecer ou apagar vestígios que impedem a passagem do dizer a outro regime de sentido, sob a ameaça de a interpretação não se efetivar e a enunciação tradutória perder-se no vão entre os discursos que disputam ideologicamente a tutela da tradução possível.

Enredado na região do simbólico, que tem a fronteira linguística como dispositivo necessário, o tradutor experimenta-se como enunciador apenas na medida em que se dá ao movimento incerto da discursividade, tomada como mola propulsora da interpretação. É este movimento que abre passagem para o dizer que se deixa despir, ante o desafio de permanecer o mesmo ainda que travestido no regime de outra língua.

Graças a um trabalho de subtração - digo subtração para dizer não da falta, mas do excesso de sentido colado ao significante - no trajeto tradutório - ao ser transposto para outra língua, o texto de partida se desorganiza submetendo-se a um novo processo de textualização. 
O procedimento desenrola-se segundo as regras de uma ordem discursiva na qual se reconhece o mesmo na particularidade de uma formulação em tradução. Assim, o valor das interferências efetuadas na escritura em ato na língua de partida reside na possibilidade de inscrever a forma textual traduzida no mesmo lugar discursivo que a tornou possível na primeira língua em que apareceu.

Proponho que, na experiência de traduzir, as diferentes formas de interpelação, na relação com a língua, produzem o tradutor na distinção entre o ato de enunciar em uma língua e o ato que agora acontece em outra. O pressuposto de que há o sentido literalizado na língua de partida a ser repetido na língua de chegada é aqui o próprio da interpelação ideológica. O texto de partida é sempre interpretação que se impõe como efeito de evidência, impondo também a forma de sujeito-tradutor em certa posição de discurso.

Mas a interpelação que torna possível a ilusória e necessária completude da tradução enfrenta uma resistência que embora se apague ideologicamente, deixa vestígios em seu percurso. Daí que a particularidade do ato de traduzir, no limiar da interpelação do indivíduo em sujeito, consiste em uma perda. Perda que não se mostra nem no ponto de partida, nem no ponto de chegada, mas no trajeto de redizer o já dito em outra língua. Acontece no processo tradutório o longo percurso que separa o texto da exterioridade discursiva $^{6}$ que o vai fazer repetir-se em formulações estrangeiras. Ainda que a paráfrase seja o ideal da forma traduzida, há múltiplos discursos no discurso que torna possível o texto na língua de que parte. Nesse longo percurso, os limites para significar são difusos perfazendo um terreno movediço de transformações no qual a ideologia tem a propriedade de fazer imaginariamente valer apenas um dos sentidos em jogo.

Pode-se rastrear aí operações enunciativas que escancaram essa instabilidade do processo tradutório. Nesse sentido, o que se postula como erro expõe vestígios de como o dizer, na falésia do sentido, é submetido a uma política que o força a alocar-se em certa memória sob pena de não sobreviver à interpretação em qualquer 
língua. Refiro-me aqui ao estranhamento do leitor diante de determinadas passagens lidas em um texto traduzido.

Para efeito de ilustração, cito aqui o caso de uma charge republicada pela Folha de S. Paulo em 1996. A charge mostra a Princesa Diana e a famosa Lisa Marie Presley em uma sala de espera da Corte de Separação Judicial conversando sobre a experiência de divórcio que ambas estavam vivendo na época. A Princesa Diana separava-se do Príncipe de Gales e Lisa Presley do cantor Michael Jackson. O texto do diálogo é transcrito no original, seguido da tradução em português logo abaixo.

“It's hard living with a Queen", diz a Princesa Diana.

"É duro viver com uma Rainha".

"Tell me about it", responde Lisa Marie Presley.

"Fale-me sobre isso."

O estranhamento localizado na leitura da charge em português conduz a comentários do tipo "aqui há um problema ou um erro de tradução". Vale a pena reproduzir uma das tantas reações diante do equívoco flagrado na tradução dessa charge.

Essa tradução é fruto de um desconhecimento sobre a língua inglesa, e mesmo o leitor não familiarizado com o idioma notaria que algo soa estranho. O humor só faria sentido se o tradutor percebesse que a frase "Tell me about it" é uma expressão idiomática que seria mais adequadamente traduzida por: "Eu que o diga." Ou seja, Lisa Marie Presley está concordando com a Princesa Diana que é realmente difícil viver com uma rainha. Só que a "rainha" a que a primeira se refere é o (então) marido Michael Jackson. O tradutor deveria deixar claro ao leitor, que o termo queen, além de significar "rainha", pode significar "homossexual"[2]. Somente então se percebe o humor da charge: cada uma se referia a um tipo de queen com o qual seria difícil conviver. 
Erros como esse são a causa das frequentes observações equivocadas sobre o senso de humor do falante da língua inglesa ${ }^{7}$.

Nesse comentário, detenho-me sobre a observação de que "mesmo o leitor não familiarizado com o idioma notaria que algo soa estranho". É que do modo como fica formulado em português o que se estranha não é tanto a presença de uma incorreção linguística - tanto nas escolhas lexicais quanto no arranjo sintático na passagem do inglês para o português nada há a surpreender -, mas sim o fato de a resposta que Lisa Presley dirige à Princesa Diana não chegar a compor uma conversa. Mesmo não considerando o equívoco que entra em jogo no emprego local da palavra queen, a levar em conta as posições em que as duas celebridades inglesas são postas em interlocução - a charge tem como referência duas mulheres públicas em vias de se divorciar -, o sentido da resposta de Lisa ressoa em outro lugar de discurso muito diferente daquele em que discursivamente se deparam. Trata-se de uma discrepância interpretativa cujo lugar de emergência se detecta no jogo diferencial do interdiscurso.

Vê-se que, neste caso, não é só um problema de transferência de conteúdo que está em questão. Recorro neste ponto ao que à noção de alusão proposta por Authier-Revuz ${ }^{8}$ como um particular fato enunciativo de não coincidência do discurso com ele mesmo. Pela alusão, pode-se observar localmente na cadeia da fala ou da escrita o sujeito da enunciação adverte, na extremidade de seu dizer, algo como "eu falo aqui com palavras alheias".

No caso do que se estranha na tradução da charge o que seria do domínio da alusão? Ela recai sobre a palavra queen (rainha), tomada aqui como termo pertinente a outro dizer. Aludir é mostrar como todo o dizer encontra-se submetido ao limite de sua exterioridade discursiva. $\mathrm{O}$ alusivo aqui diz respeito ao lugar da memória discursiva em que o dizer "queen" tem relação com os enunciados nos quais um de seus sentidos aparece como um modo de designar 
alguém a partir de sua suposta orientação homossexual. É interessante observar que não se trata aqui de um mero jogo de palavras. Adotando a abordagem de Authier-Revuz, no modo com que é enunciada a palavra faz jogo não com outras palavras da língua, tal como no trocadilho, mas com as palavras de outros dizeres, ou seja, quando a Princesa Diana diz queen enuncia como se fizesse sua voz ecoar sob outra ressonância discursiva, ou, na expressão de Authier-Revuz, como se através da sua, deixasse passar "a música de outra voz".

Mas, nos termos em que Authier-Revuz teoriza sobre esse fenômeno de insinuação discursiva, a alusão tem a propriedade de apresentar-se e permanecer enquanto tal com sua localização em discurso a descoberto. Em outros termos, basta o estranhamento, basta a interceptação de outro tom no trajeto dos sentidos para que se encontre um caso de alusão. Desse modo, a perplexidade do leitor reside no fato de não saber qual o ponto de referência da afirmação de Diana e a resposta de Lisa. Somente pela identificação, mediante a memória discursiva, do jogo de sentidos no qual a palavra queen é enunciada pode-se recuperar que: a tradução literal de "Tell me about it" por "Fale-me sobre isso", alude a um já-dito, recoberto pelo caráter idiomático da expressão. O risco da alusão é de levar o dizer à perda da memória de discurso que o sustenta como jogo. $\mathrm{O}$ que se perde, então, não é tão somente um dado linguístico, mas um denso processo discursivo que fica sem abrigo na língua de partida e custa a abrigar-se em outro na língua de chegada.

Retomando o que postula Authier-Revuz há ainda um déficit inerente ao jogo da alusão, na medida em que, conforme a critica citada anteriormente, ao não alertar que "o termo queen, além de significar "rainha", pode significar "homossexual", o tradutor priva um certo grupo de leitores do prazer da conivência discursiva a que se aplica a estratégia do humor na charge. Num caso como este, o recurso à nota de rodapé entra sempre como o expediente que elucida localmente no texto traduzido a presença de uma alusão ali onde se nota uma estranheza no dizer. Embora o recurso expresse a elegância do tradutor que, através de uma notação pontual, 
amplia a rede de compreensão da relação de sentido presente no texto, permanece no mesmo gesto a acentuação de um destino seletivo inerente à alusão. Em outros termos, o tradutor detém, contra qualquer competência linguística partilhável com o leitor, o lugarchave que abre para uma estratégia complexa de discurso.

Assim é que se pode reportar os fatos linguísticos de dificil passagem como o traço que desenha a fronteira entre a fala estrangeira e a própria. Trata-se da marcação da diferença que, sob uma maneira alusiva de dizer, se mostra enquanto tal perturbando a fluência da escritura que transita da língua do outro para a própria. A estranheza apresenta-se em sua incapacidade de completude; em sua impossibilidade de circunscrever o dizer em dada ordem de discurso. Aí é que se detecta uma espécie de falha que se pode descrever através do que Authier-Revuz ${ }^{9}$ propõe como o próprio da alusão faltante: $o$ ato de enunciação que não incorpora a diferença que faz furo em um ponto da superfície do dizer "atravessado pela presença do espectro de um discurso outro pairando sem voz e forma no fluxo da fala em língua própria”.

\section{Do sujeito que se perde}

Se não há subjetividade sem a passagem pela língua como horizonte, o que se passa quando o dizer que constitui o sujeito submete-se a mais de uma língua? Ainda que sem espaço para discorrer sobre a questão, o pressuposto de base é o de que conceitualmente aquela em que o sujeito é produzido só pode ser a língua materna. Esta tem como traço inerente sua própria ordem que simbolicamente a distingue de outra e acolhe como estranho tudo o que não coincide com as regras dessa ordem. Por mais que domine outras linguas diversas da sua, inconscientemente o falante só se reconhece sujeito na sua própria língua.

A estranheza da passagem por outra língua remonta à experiência do dizer lançado à sua própria sorte no campo em que, tal 
como postulou Derrida, há uma "diferença de sistema de línguas inscrita numa só língua" que não se deixa passar. Por certo, essa diferença remete ao domínio de discurso em que a língua conectase com a história. A propósito, vale aqui remeter ao que Foucault alude sobre a remisssão analitica do enunciado à língua e ao discurso. Apesar de irredutível em seu sistema de regras, a língua não deixa de sucumbir ao acontecimento discursivo, horizonte no qual, independente da sitematicidade que as constituem, as línguas se estranham resistindo-se mutuamente como território de recepção de formulações estranhos às discursividades que tornam possível nela enunciar dados sentidos e não outros.

Eis a questão que a análise da língua coloca a propósito de qualquer fato de discurso: segundo que regras um enunciado foi construído e, consequentemente, segundo que regras outros enunciados semelhantes poderiam ser construídos? A descrição de acontecimentos de discurso coloca uma outra questão bem diferente: como apareceu um determinado enunciado, e não outro em seu lugar? ${ }^{10}$

Daí que a impossibilidade da passagem, dada pela ausência de posição de discurso conectável à língua de chegada, aponta para a experiência escritural em que o tradutor depara-se com o real na língua e na história deixando vestígio nas dissonâncias entre o texto de partida e o de chegada. Se na forma primeira, o texto mobiliza a língua constituindo nela e com ela o dizer já significado, na versão segunda só retoma o mesmo dizer a partir do discurso que o tornou possível em outro sistema linguístico.

Nesses termos, a retomada de uma enunciação em outra língua expõe o sujeito que traduz a uma experiência provisória e necessária de dessubjetivação, já que o transporte do dizer de uma para outra língua implica também a composição incerta de uma posição de sujeito possível na língua. Tal transposição demanda abertura e retirada. De um lado, abertura para a multiplicidade de senti- 
dos que assaltam o dizer em seu trajeto de uma cadeia a outra de enunciação De outro, retirada de lugares fixados de dizer como condição à passagem para a função enunciativa que faz autoria fora do si do sujeito-tradutor constituído em língua própria, deixando-se enunciar em língua estranha.

Mas tal movimento de produção de formas de sujeito não decorre de uma escolha. Ainda que o tradutor exiba a consciência de que, embora escrevendo na sua língua, dá passagem a uma escritura alheia, essa consciência é dada historicamente em uma ordem de discurso que assim o determina dispondo modos de interpelação constitutivos do sujeito-autor na diferença com o tradutor. Um indivíduo, "Um único e mesmo indivíduo", diz Foucault, "pode ocupar sucessivamente em uma série de enunciados diferentes posições e exercer o papel de diferentes sujeitos" ${ }^{11}$.

Assim é que se pode delinear essas posições na forma respectivamente do sujeito que cria e do que traduz. Trata-se, desse modo, de uma muito particular modalidade de deslocamento de posições do sujeito. Sob esse aspecto, a atribuição de nome ao que formula em outra língua e ao que traduz não é da mesma natureza. Intervém aqui o regime da ordem discursiva que estabelece as regras do aparecimento do autor como função.enunciativa.

Contudo, resta algo em comum na formação do nome para o autor e para o tradutor, ainda que o estatuto de ambos não seja os mesmos diante da obra em estado de tradução: o ponto de encontro localiza-se na mesma experiência que ambos fazem da heterogeneidade da língua e do dizer. Ao traduzir, o sujeito que traduz retoma a árdua passagem do significante ao discurso tal como experimentou o que criou o escrito. Ambos tornam-se alvo da doação do nome no recorte que delimita a singularidade entre o gesto de escritura e o produto dele. Nisto consiste a perda no ato de traduzir. 


\section{Notas}

1. ORLANDI, E. Interpretação, autoria, leitura e efeito do trabalho simbólico. Rio de Janeiro: Vozes, 1996.

2. PÊCHEUX, M. Analyse Automatique du discours. Paris: Dunod, 1969.

3. PÊCHEUX, M. Discurso, estrutura e acontecimento. Campinas: Pontes, 1991.

4. Op. Cit, 1991.

5. Daí que a história não existe senão pela língua e pelo discurso; a história não passa de acontecimentos inseridos em uma trama de sentidos (cf. HENRY, P. "A história não existe?”. In Gestos de Leitura. Orlandi, E. (org.). Campinas: Editora Unicamp, pp. 29-54, 1994).

6. ORLANDI, E. Discurso e texto: formulação e circulação dos sentidos. Campinas: Pontes, 2001.

7. ALMEIDA, Virgílio Pereira. "As dificuldades do mau e do bom tradutor". In < http://www.humanitates.ucb.br/1/traducao.htm > . Humanitates, Volume I - Número 1 - Setembro 2004 - ISSN 1807-538X. Brasília, Centro de Ciências de Educação e Humanidades - CCEH -Universidade Católica de Brasília - UCB.

8. AUTHIER-REVUZ. Jacqueline "L'allusion : le dire aux risques du déjà dit", in $D u$ nouveau dans les discours, Horizon 23, Ecole de la Cause freudienne, juin 2000, 26-28.

9. AUTHIER-REVUZ, J. Aux risques de l'allusion", in L'Allusion dans la Littérature, M. Murat éd. (coll. Colloques de la Sorbonne), Presses Universitaires de Paris-Sorbonne, 2000, p. 209-235.

10. FOUCAULT, M. Arqueologia do Saber. Trad. Luiz Felipe Baeta Neves. Rio de Janeiro: Forense-Universitária, 1986, p. 43.

11. Idem, idem, p.43. 